\title{
The New Series of \\ The AnaChronisT
}

\section{Zsolt Komáromy EDITOR-IN-CHIEF}

Since 1995, The AnaChronisT has been a forum of research published under the auspices of the Department of English Studies at Eötvös Loránd University, Budapest. As the journal's founder Ágnes Péter summed up its mission in the opening issue, "it is vital to create an intellectual ambience that would encourage a spirit of adventure, a hunger for the new, while preserving a respect for the more traditional scholarly practices worthy of our attention." The AnaChronisT met a demand larger than initially envisioned, and soon became a major forum in Hungary for graduate students and academics publishing in English, and attracted authors from all over Europe, and even beyond, growing into an international scholarly journal, indexed by major bibliographies and databases.

The journal discontinued publication in 2014 due to financial reasons. But we have received many encouraging words, ensuring us that the scholarly community in which we work felt that the journal's termination was a loss, and would welcome its relaunching. Most of the members of the original editorial and advisory board were willing to continue work with the journal. After negotiations with L'Harmattan publishing house, Budapest, whose dedication to scholarship is exemplary, and who's business expertise was a major factor in the success of renewed attempts at finding financial resources, the journal has now been relaunched.

We call this and the ensuing issues the New Series of The AnaChronisT because we have slightly changed its profile and publishing policy. Originally, each issue was a medley of articles, irrespective of subject matter. In the New Series, we plan to publish partly or wholly thematic issues. There have also been some personal changes. Géza Kállay, who was editor-in-chief between 2009 and 2014 has tragically passed away. His memory and his unceasing inspiration continues to be a source of energy for work with the journal. Ágnes Péter, the founder of the journal and 
editor-in-chief until 2009 has in the meantime retired, but she accepted our invitation to take a place on the Advisory Board and to keep lending us her knowledge, expertise, and wisdom. Boldizsár Fejérvári, our technical editor, whose ideas and work ensured the distinctive design and layout of the journal could not join the work on the New Series, and we thank him for his immense contribution in the past, as well as for continuing to advise us, and for sharing his knowledge with Bence Levente Bodó, who took on the task of redesigning the appearance of the journal with professionalism and commitment. I thank all the editors wo decided to return to the journal for their dedication. In our first venture, we have also joined forces with a new generation of graduate students at Eötvös Loránd University, whose energy and inventiveness in initiating and organizing scholarly work was an inspiring example for relaunching the journal, signalling that the dire financial situation of the University and the deteriorating working conditions of scholars in Hungary have not led to apathy. We hope that the New Series of The AnaChronisT can do its part in maintaining commitment to scholarship, and live up to its tradition of creating a space for the quality work of a community of scholars of different generations and fields of study, in and beyond Hungary. 